\title{
A Review on TAM and TOE Framework Progression and How These Models Integrate
}

\author{
Julies David Bryan*, Tranos Zuva \\ School of Applied and Computer Science, Department of ICT, Vaal University of Technology, Vanderbijlpark, 1911, South Africa
}

\begin{tabular}{l} 
A R T I C L E I N F O \\
\hline Article history: \\
Received: 08 December, 2020 \\
Accepted: 27 March, 2021 \\
Online: 20 May, 2021 \\
\hline Keywords: \\
TAM \\
T-O-E \\
Limitations \\
Criticism \\
Trust \\
Reliability \\
Pricing \\
Technology context \\
Organisation context \\
Environment context \\
\hline
\end{tabular}

\section{Introduction}

Research studies on IT adoption have rapidly evolved over the last three decades. A diverse number of theoretical models have been created such as Innovation Diffusion Theory (IDT), Theory of Planned Behavior (TBP), Diffusion of innovations (DOI), Electronic Data Interchange model (EDI), etc. Two of the most valued research studies that contribute to IT adoption are Technology Acceptance Model (TAM) and TechnologyOrganization-Environment (T-O-E).

In the 1970s, anticipating system growth became a niche of attraction to many researchers due to the growing technology demand and system adoption failure that goes with it [1]. According to [2] the vast majority of studies neglected to deliver solid estimates that could clarify framework acknowledgment or dismissal and recommended Technology Acceptance Model in 1985 [1]. Davis proposed that the user interaction with any system is a reaction that can be interpreted and foreseen by user inspirations, shaped by foreign catalyst [1]. As per [1] user inspirations are shaped through a foreign catalyst that abides system's features and capabilities. Davis, who counted on preceding work done by [3] continue amend his model and

${ }^{*}$ Corresponding Author: Julies David Bryan, bryanjul@gmail.com

Www.astesj.com

https://dx.doi.org/10.25046/aj060316 propose the Technology Acceptance Model in which he advises that user motivation can be driven by three factors:

- $\quad$ Perceived Ease of Use (PEOU)

- Perceived Usefulness (PU)

- Attitude towards using the system. (A)

According to [1] Davis's thesis on user's attitude towards a system is a major factor that determents if a user will use or reject a system. A user's attitude is leverage by perceived usefulness and perceived ease of use.

Broad literature on Information Technology (IT) appropriation demonstrates that there are a few investigations at the individual level [4]. Numerous theories and models uses IT adoption at the individual level such as Technology Acceptance Model (TAM) $[1,2,4]$, Theory of Planned Behaviour (TPB) [3], TAM 2 [5] Unified Theory of Acceptance and Use of Technology (UTAUT) [5]. However, studies show that there is less investigation at organisational level.

According to [6] the whole process is an innovation from development by engineers and business people to the adoption and execution of those advancements by clients inside the context of 
an organization. As per [7] the T-O-E framework performs the process of how the organisation impacts the appropriation and execution of innovations. As per [7] the T-O-E framework is an association hypothesis which clarifies three unique components association's setting impact reception choices. The components are technology, organisational and environmental context, and each of the three is set to impact technological innovation. [6] built up a structure for hierarchical reception dependent on the Contingency Theory of Organisations. According to [3] the strength of a organisation is determined by both internal and external elements which can be described as environment, organisation size, and organisation strategy. Upon decision making three key elements environmental, organisational and technological needs to be factored in, and organizational adoption is based on technology, organisation, and environment [4].

The contribution of this paper is to determine and understand usage and modifications, progression, limitations, and criticisms of the Technology Acceptance Model (TAM) and TechnologyOrganisation-Environment (T-O-E). The paper also looks at how these two models can be integrated to complement one another.

\section{Technology Acceptance Model (TAM) Overview}

As per [8], [2] established the Technology Acceptance Model (TAM) by assuming that users will perceive usefulness to technology through ease to use as they become willing to use the technology. When employees realize that the new technology will make their life easier and more productive the greater the odds are for them to use and accept it [8].

As per [1], with the rapid technological growth in the 1970s, many organizations struggled to adapt to system failure. Due to the increasing system failures, numerous researchers started to study the area of predicting systems [9]. The TAM was then proposed by [10] in 1985 during his studies at MIT Sloan School of Management [1]. According to [1], Davis proposed that system usage is a human behavior that is user motivation driven and directly influenced by external stimulation like system's components and efficiency. This can be seen in the Figure1 below.

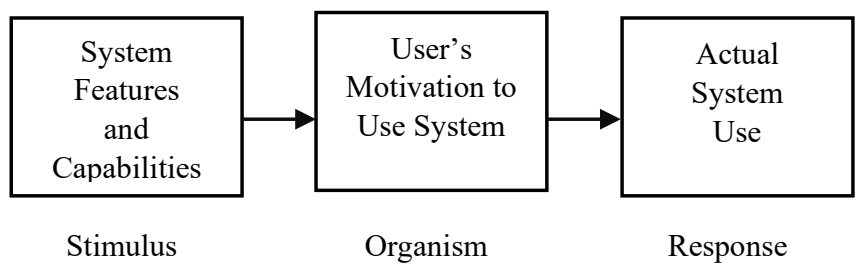

Figure 1: Model for technology acceptance [22].

Davis then continued with his research by relying on prior work done by [11] on the Theory of Reasoned Action. The refined model of Davis can be seen in Figure 2.

In Figure 2, [11] propose that user motivation can be described by three factors: Perceived Ease of Use, Perceived Usefulness, and Attitude Towards Using the systems [1]. As per the [9] Davis model, TAM hypothesized that attitude towards the system is a considerable factor whether used or rejected by the user. User's attitude is influenced by two primary convictions namely perceived usefulness and perceived ease of use.

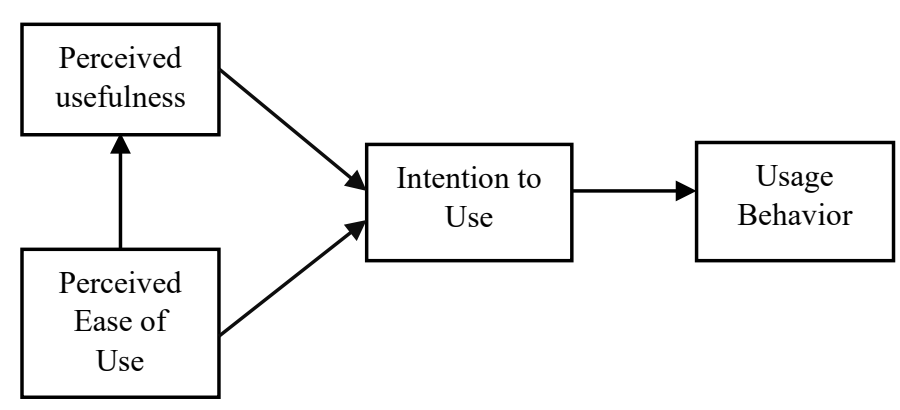

Figure 2: Original TAM [11].

According to [12] on the contrary, states that the TAM theory is based on social behavior by someone's attitude which is predicted to use an information system. [3] argue that when it comes to personal use of technology, social influences like friends and colleague is a major factor. However, when it comes to the organisations, the work climate cannot be controlled by follow workers but the organisation regulate direct the conduct of the workers as there is rule-administered conduct at organisations for utilizing a system. [8] states that TAM is simple and easy to understand and is mention by [13] to be the most popular means of measuring the scale of acceptance of technology by users.

TAM studies the individual relationship of technology acceptance, adoption, and BI to use [6,14]. As per [13] and [14], the main factors for system use with TAM is PU and PEOU. PU can be described as "the prospective user's subjective probability that using a specific application system that will increase his or her job performance within an organisational context," and PEOU is defined as "the degree to which the prospective user expects the target system to be free of effort" [2]. As per [15], PEOU influences PU because of its ease of use making TAM a popular model. It has been proven by numerous research studies that these two variables are frequently used for testing and [14] stated that these PU and PEOU variables are mentioned 40 percent for people's goal to utilize (admission) and resulting execution (transformation) of technology. TAM hasn't only been developed to predict user adoption, but it was also designed to predict user behavior after the individual has interacted with the system [16]. The TAM model is supported as a goal-based model which specifies that the goal to embrace innovation is a decent indicator of its genuine use [16]. Henceforth, it very well may be reasoned that the TAM model got solid ramifications for technology endorsements from conceptual and theoretical perspectives. [6]. [17] declares the primary reason why TAM was developed was to model user consent for IT with the desire to explain the BI system usage that was a footing for IT dealing with BIs and usage of IT [17]. [6] states that to have a better overview on IT adoption and acceptance, the primitive framework (i.e. TAM2 and TAM3) had to be extended and includes PU and PEOU categories. There were four modifications that assisted with the TAM evolution, these can be named as adjusting outer precursors; changing prescient factors; controlling mediator factors, and shifting outcome measures [13] and [18]. The underlying center segment basic to all alterations of TAM comprises of three builds: PU, PEOU, and BI $[13,18]$ and in the centre part, $\mathrm{BI}$ is influenced by $\mathrm{PU}$ and PEOU, PU is affected by PEOU. It is concluded by [18] and [3] PU and PEOU are two 
centre develops that shape client perspectives and aims in adopting a technology system.

In summary, the TAM model is widely used to understand IT adoption and usage process according to [6]. The reason for its popularity as per [16] is that the model clarifies variance like behavioural intention (BI) applicable to IT adoption of use overbroad contexts. Another reason why TAM is so famous is that it foresees an owner's IT consent by the user and the job usage [14]. [1] on the contrary, states that the reason why it is widely used is that TAM explains the determinants of user acceptance of a wide range of end-user computing technologies.

\section{Limitations and Criticism of TAM}

Even though TAM is popularly used, it does come with limitations and these are found in moderating and external variables [13]. TAM looks at future behaviour and not on actual behaviour $[15,18]$ as this also aids to its limitations. [13] confesses that TAM is known for its restricted chance of clarification and expectation, detail and absence of common-sense worth.

A crucial extension to TAM by [19] was to introduce TAM2 as TAM had some limitations in illustrating reason for a person to perceive system usefulness. For this reason, additional variables were added to the perceive usefulness variable in TAM [9]. A second important alteration to TAM by [19] was identifying the decedent to the perceived ease of use variable in the TAM model. For this reason, two new decedents namely anchors and adjustments were added. As per [9] anchors were thought-about personal computers and the usage of it, well adjustment was thought-about as direct involvement with the target system. Other limitations stated by [9] has been flagged by numerous researcher and has grouped the criticism into three categories:

\subsection{Limitations in the methodology used for testing the TAM model}

The biggest criticism of TAM is the model makes use of selfreport use data instead of measuring against real system data. According to [20] self-report data is abstract and inaccurate when measuring system usage. Even so, many studies still make use of self-report use data. As per [21] the TAM model makes use of students as participants in a controlled environment to obtain test results and for this reason, these test results cannot be generalized to the outside world as studies have distinctive intentions like obtaining grades, rewards, etc. [20, 22].

\subsection{TAM model variable and relationship limitations.}

According to [23] attitude is an important factor for system usage and TAM needs to review it. The TAM model was clone in 1998, but the attitude variables were not removed as proposed by [21], instead, two additional attitude variables, affective and cognitive were added. [21]. A survey by [23] requested participants to rate their usage of spreadsheet applications. The outcome of the survey shows that the effective attitude variable did not portray the statistical connotation to anticipate system use however the results on the cognitive attitude were very significant.

\subsection{TAM model theoretical foundation limitations.}

According to [24], the poor hypothetical relationship was defined among the various builds detailed in TAM. He scrutinized the hypothetical quality of the goal real use connect, and saw that conduct couldn't be considered as a terminal objective. [24] claims that conduct should be treated as a way to a more terminal intention and behavior should be a fundamental target. Besides, he clarified that the aim may not hold delegate enough of real use, because the time-frame among goal and appropriation could be full vulnerabilities and different elements, that may impact a person's choice to embrace innovation. In [24], likewise scrutinized the chance of deciding conduct by including measures for perceived usefulness and perceived ease of use.

"There is a scope of investigating the role of certain other variables such as technological influences, the role of firm size in the technology make/buy decisions, the innovativeness of the firm, a firm's level of technology readiness, security, trust, marketing effort and also on evaluating the consequences of technology usage on performance such as responsiveness and financial performance" $[15,18,25]$. It must be noted by [26] that the TAM has been used in almost every IT research adoption theory and because of its frequent use, the quality of TAM could be at risk, as this could lead to degreed in the research field. Another limitation mentioned by [20] shows that TAM experimental investigations don't deliver predictable or clear outcomes and proves that demonstrates the TAM model needs to be incorporated with other IT reception models and hypotheses.

\section{Technology Acceptance Model (TAM) progression}

As per $[13,27,28]$ the TAM is a principal adoption theory in the IT sector. TAM discloses how external variables can have an impact on adoption decision making on fundamental financial, functional, and beliefs and therefore recommends PU and PEOU as the central reason for adoption in IT [9]. An individual's goal to exploit an application is interpreted and forecast by his view of the innovation's handiness and its straightforwardness. According to [19] perceived usefulness can be determined by both perceived ease of use and predict attitudes. Over the years TAM has shown great acceptance, utilization, and reproduction but the model failed to give essential data on the user's assumption for only PU and PEOU. Based on this limitation it was necessary for the model by expanding or integrating with other IT acceptance models [9]. The integration of TAM with different models enhanced TAM by including utilization and putting premiums in explicit settings and outside factors that impact an innovation's appropriation procedure [9].

According to [7] many studies have been made to the original TAM model the causes the model to evolve. TAM-TBP was a new model introduced by [16] to integrate TAM and the theory of planned behaviour (TBP). In 2000, TAM2 was developed by [19] that extended new variables to the existing model. In 2003, the Unified Theory of Acceptance and the Use of Technology (UTAUT) model was proposed. There have been numerous studies made by scholars to alter the TAM by adding new variables. The Construct of Compatibility variable was added in 1998 by [13].

New playful factors were added by [29] to examine the acceptance of the Internet. Variables like "experience", "selfefficacy", "perceived risk", and "social influence" were added to the TAM model by [30]. An additional study made by [17] helped to extend cognitive absorption, playfulness, and self-efficacy. In 1996 two types of perceived usefulness namely near-term and 
long-term were added [2]. In 2000, two new constructs were added to TAM namely perceived entertainment value and perceived presentation attractiveness, [11] was the scholar for this addition. Peer influence was then combined with TAM in 2002 by [3, 7].

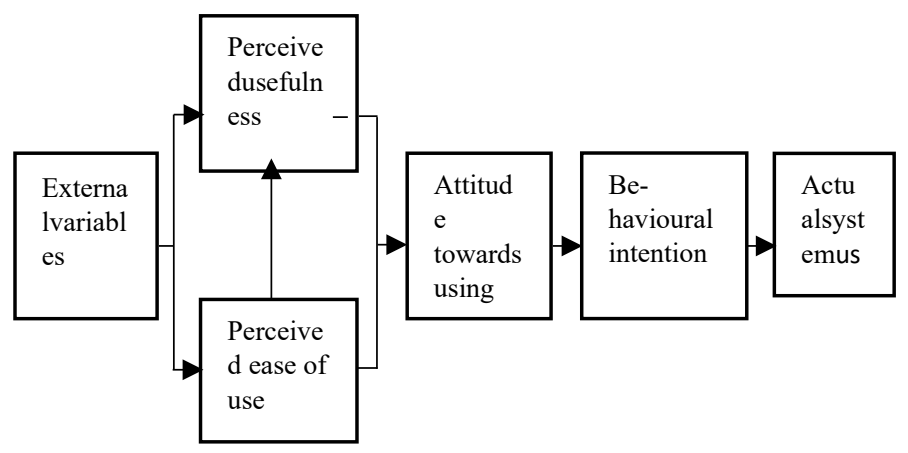

Figure 3: Technology Acceptance Model [30].

TAM has been used by scholars around the globe to perceive the acceptance of completely different sorts of information systems. A newly developed model by [6] based TAM named the shopping acceptance model (OSAM) was created to study online shopping behaviour. In 2003, in [31], the author developed an ecommerce model based on TAM with new variables trust and perceived risk.

\section{Technology-Organization- Environment (T-O-E) Overview}

As per [4], T-O-E Framework was developed by [6] for organisational adoption based on the Contingency Theory of Organisations. Well, it is claimed by [9] that [6] expect a nonexclusive arrangement of components to anticipate the probability of adoption. The framework proposes that an organisation should be consistent with its surroundings and environmental needs and its strength is determined by both internal and external factors like environment, organisation size, and organisation strategy [3]. Three key determinants were distinguished that influence organisational adoption: technology, organisation, and environment. It is imperative when one is making a decision, three factors of influence need to be looked into namely technology development [80] organisational conditions, business and organisational re-configuration [2], and industry environment [27].

Within the T-O-E framework, technological development presents the technologies accessible to an organisation. The organisation context outline the organisation characteristics well the environment context outlines the business field that consists of industry, competitors, regulations, and relationships with the government. As per [6], these are external factors that can have restraints and opportunities for technological innovations. The drawback of T-O-E is the assumption that the model will apply to large organisations, where customers make certain of congruity and fewer grievances, than to SMEs [9].

According to [6] there are three contexts that leverage technology innovation adoption and implementation process and these contexts of the T-O-E framework can be listed as follows.

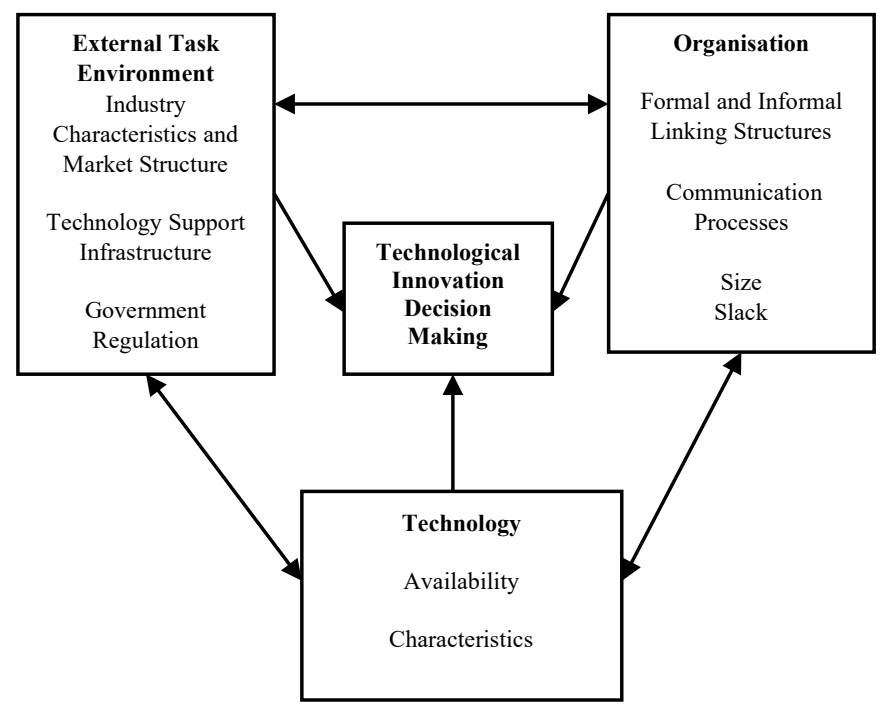

Figure 4: The technology-organization-environment framework [7].

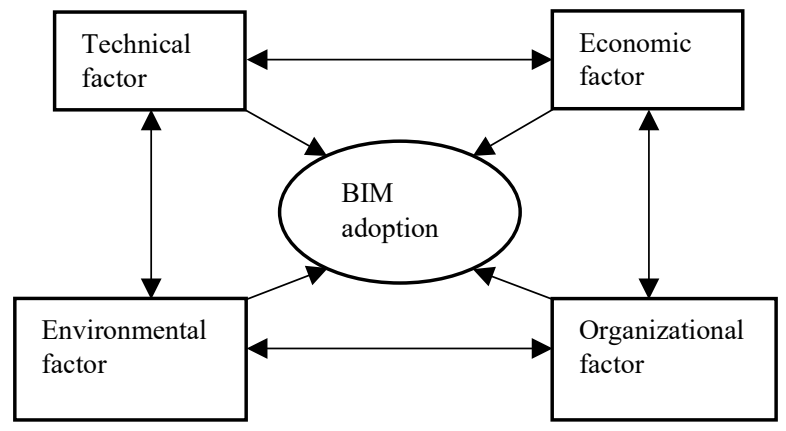

Figure 5: The derivative of T-O-E framework of BIM technology [30].

\subsection{Technology context}

In [2] and [16], the author defines that the technology context consisting of variables that has an impact on an individual, an organisation, and an industry's adoption of innovations and comprises of five innovation attributes as per [32] and [16] and also other attributes. Aside from innovation variables, other significant variables like system absorption, digestion, trail ability, intricacy, seen direct advantages, seen backhanded advantages and normalization has been included by several research studies while observability is found insignificant $[1,2,9,12,18,22,32$ 34].

\subsection{Organisation context}

Adoption aptitude is impacted by explicit and spontaneous intra-hierarchical components for correspondence and supervision; along with resources and creativity of the organisation [32]. In [4], the author states that organisational context comprises of organisation scope, organisation size, and legislative belief. As per $[1-3,9,12,18,22,32,33,35]$ the most important variables of organisational context includes "financial resources, firm structure, organisational slack, innovation capacity, knowledge capability, operational capability, strategic use of technology, trust, technological resources, top management support, support for innovation, quality of human capital, organisational knowledge accumulation, expertise and infrastructure, and organisational 
readiness while financial capacity and technology competence are identified as insignificant". The clarification explained by the makers is, relationship of all sizes have perceived the fundamental meaning of development for the achievement of their associations, consequently are glad to contribute enthusiastically to progressions to improve their high grounds. [12, 32, 34]; states that the role of top management is not the same and differs in context. As per [2] some inter-organisational variables context are on EDI that identifies the power of partners, an expectation in the partner and tie responsibility with a partner and dependency of the partner.

\subsection{Environmental context}

Environmental context is an area where the company targets business operations like government incentives and regulations [4]. The environmental context consists of variables like rivalry, relations with buyers and suppliers, and areas of the industry life cycle $[2,4,6,9,12,18,22,24,32-34]$ says the environmental context variables covers client order, serious weight, outer weight, inside weight, exchanging accomplice pressure, merchant uphold, business reliance, ecological vulnerability, data power and organisation force.

In summary, T-O-E has materialized to be a widespread framework used for theoretical perspective on IT adoption [24]. Consideration of technological, organisational, and environmental variables has made the T-O-E frame invaluable over other selection models in contemplating innovation appropriation, innovation use, and worth creation from innovation development $[2,8,9,32,36]$.

\section{Limitations and Criticism of T-O-E framework}

As per [32] the T-O-E framework limitation as glossary of variables that is not well integrated or well developed and needs more research study on organisational adoption. [1] likewise featured that T-O-E system has no significant develops in the model and the factors in every unique circumstance [33] states that there lack in power of technology and adoption variance is unexplained. On the contrary [12] declares that the major constructs and the variables in the T-O-E framework are not concise and differ from context to context. For this reason as by $[9,35]$ and $[3,12,24,32,36]$ other variables like sociological variables, cognitive variables, technology readiness, ability to leverage IT investment through different channels professionals' experience and skills, managerial capabilities of change management, security concerns, government promotion and factors salient to the country context such as government policy/regulation, technology infrastructure, and culture is needed to refine the T-O-E framework.

\section{Technology-Organisation-Environment (T-O-E) progression}

According to [37], the T-O-E framework lack change for different reasons from original development. This lack of evolution can be described as follows. Firstly, as per [24], T-O-E characterizes as a universal theory as T-O-E is used as a framework in which a large group of different elements can be set. For this reason, researchers and scholars saw little need to change or refine the T-O-E framework. Second, the T-O-E structure may have seen generally little advancement because it has been seen as lined up with other adoption model theories. For this reason, pressure has been seen by the T-O-E framework and other theories for the T-O$\mathrm{E}$ framework to assimilate in contesting innovations. As per [38], it can be seen that the T-O-E framework has been persistent with the theory of the diffusion on innovation (DOI). For example, DOI adoption on individual leader characteristics and internal characteristics of organisational structure is equally yok to T-O-E's organisation context element. Another consistency can be seen with DOI's external characteristics of the organisation with T-OE's environmental context. Lastly, consistency can be seen in the technological characteristics of the innovation with T-O-E's technological context $[39,40]$. Since these theories are portrayed as notably comparable, the T-O-E system has not been adjusted because of DOI [37].

As per [9] several research studies explains the essence of the T-O-E framework which can be explained as e-commerce Enterprise Resource Planning, e-business, , open systems, Knowledge Management Systems, Electronic Data Interchange etc. in Table 1.

Table 1: Organisational Adoption of Information Technologies

\begin{tabular}{|l|l|}
\hline \multicolumn{1}{|c|}{ Author(s) } & \multicolumn{1}{c|}{ Domain } \\
\hline$[2]]$ & "Internet/E-Business" \\
\hline$[21]$ & "HRIS" \\
\hline$[2]$ & "Green IT Initialization" \\
\hline$[67]$ & "E-Business" \\
\hline$[3]$ & "KMS" \\
\hline$[32]$ & "Enterprise Systems" \\
\hline$[37]$ & "Mobile Commerce" \\
\hline$[18]$ & "E-Business" \\
\hline$[16]$ & "ERP" \\
\hline$[2]$ & "Web Site" \\
\hline$[6]$ & "E-Commerce" \\
\hline$[41]$ & "IT" \\
\hline$[32]$ & "E-Signature" \\
\hline$[3]$ & "E-Commerce" \\
\hline$[37]$ & "E-Business" \\
\hline$[2,25]$ & "E-Business" \\
\hline$[6]$ & "Internet" \\
\hline$[6]$ & "E-Business" \\
\hline$[32]$ & "E-Commerce" \\
\hline$[27]$ & "IT" \\
\hline$[2]$ & "Open System" \\
\hline
\end{tabular}

Over the past 30 years, the T-O-E framework has exhibit influence across many technological, industrial, and national/cultural contexts [7]. The T-O-E framework has been used across various industries to explain the adoption of interorganisational systems [2, 42]. E-business [2, 6, 7, 15], electronic data interchange (EDI) [42], open systems[2], enterprise systems [32] and a broad spectrum of general IS applications [2]. The T$\mathrm{O}-\mathrm{E}$ model has been used to clarify the selection of advancements in a large group of ventures, including manufacturing $[2,15]$ health care [34] retail, wholesale, and financial services [15]. According to $[2,7,15]$ and [6] the T-O-E model has been approved in European, American, and Asian contexts, as well as in both 
developed as well as developing countries. In every one of the experimental investigations that test the T-O-E system, analysts have utilized somewhat various elements for technological, organisational, and environmental contexts. [7] claims that researchers agree with [6] that the three T-O-E contexts affect adoption, however, they have speculated that for every particular innovation or setting that is being contemplated, there is a special arrangement of components or measures. [6] argues that one relevant factor in technological context that influences the adoption of e-business is " technology readiness." [6] also states that "firm size", global scope" and "financial resources are the appropriate elements that ought to be concentrated to see how organisational context influences the adoption of e-business. When looking at environmental context influences, "regulatory environment" and "competition intensity" are suitable in the adoption of e-business.

\section{Integration of TAM and T-O-E framework}

As per [30] the creation of TAM by [2] was in light of the Theory of Reasoned Action (TRA) in 1989. [2] perceived that a person's behavioural intention to use a newly created system is associated with their perceived usefulness and ease of use. Meanwhile, the perceived ease of use influences perceived usefulness, and the perceived usefulness and ease of use are influenced by foreign variables.

As per [43] the T-O-E framework persuades models of technological, organisational, and environmental backgrounds to adopt and achieve technological innovations. he goes on to say the technological context indicates internal and external technologies by firms, organisational context refers to company size, organisational structure, and human resource, well environmental context looks at components like competition, partners, and industry environment that out-side the control of a firm [30].

The Technology Acceptance Model and Technology Organisation Environment System have been generally applied in I.T. and data innovation across various research studies [30]. The two models complement each other as TAM is flexible with external variables and can abduct a person's acceptance behaviours while on the other side of the coin T-O-E acknowledges the technical, environmental and organisational elements that have an effect on technology acceptance and adoption at organizational level. Many research studies where TAM and T-O-E are integrated can be found. [24] has integrated TAM and T-O-E to illustrate cloud adoption at organisational level. Another study by [34] evaluates system factors in the adoption of ERP in manufacturing companies. Lastly, [28] set up the UTAUT-T-O-E technology acceptance model framework and investigated the components influencing IT selection [30]. Figure 6 illustrates the integration of TOE External variables to TAM.

Joining the TAM in Figure 3 with the TOE structure in Figure 5, an incorporated TAM-TOE model for BIM innovation was created as seen in Figure 7.

The impact scale of each factor on different variables are determined through their logical relationship in the system to shape the immediate impact network, at that point the reason and focus level of each factor is determined to decide the circumstances and end-result between the elements. This strategy can visually demonstrate the logical relationships between factors through determinant analytics and can disentangle complex issues.

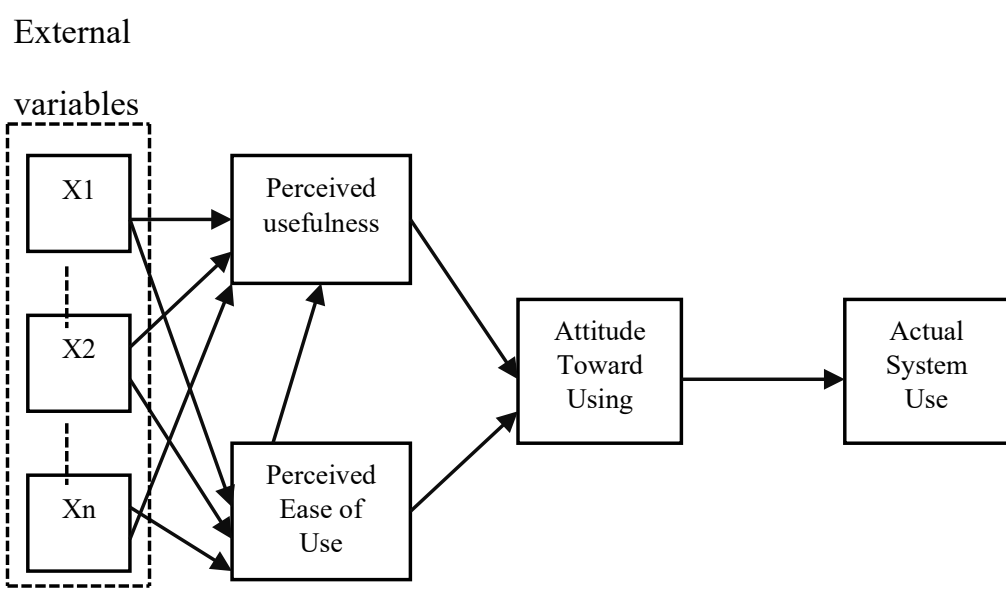

Figure 6: TAM-TOE derivative integration model [30].

External

variables

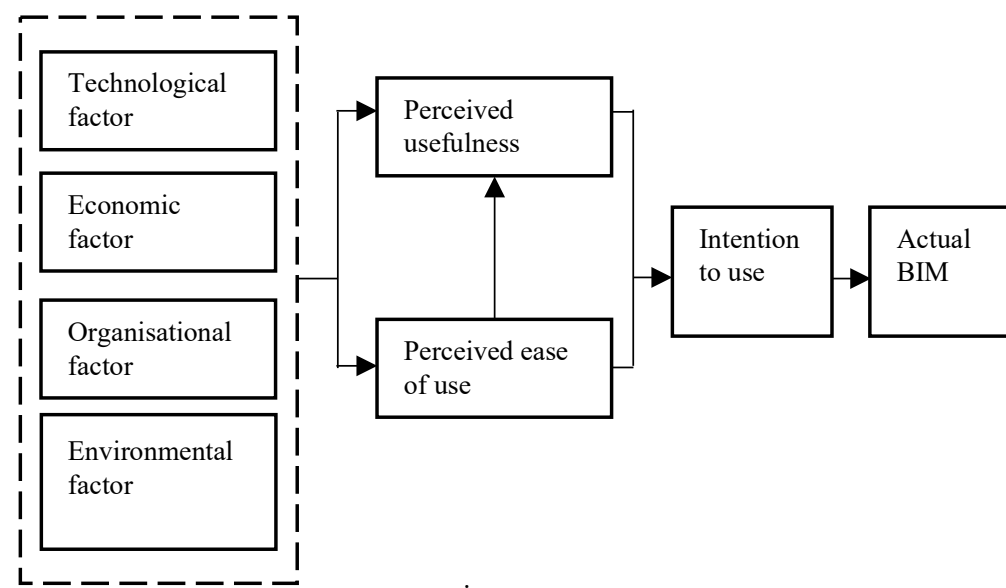

Figure 7: The derivative integrated TAM-T-O-E model of BIM technology [30].

\subsection{Technical factors}

According to [30] technical factors can be classified into three past research studies, namely localization, standardization, and compatibility.

- Localization: Localization as per [13], Building Information Modelling (BIM) consists of software operating environment, the adaption of ventures, and management process.

- Standardization: Specifies milestones, deliverables, and objectives to accomplish.

- Compatibility: This describes the strength and challenges of different application software from a different corporation, their integration, and are compatibility with each other.

\subsection{Economic factors}

According to [30] there two economic factors: cost and return in investment.

- Cost: Cost normally consist of hardware, software, training and consulting fee for professionals [59].

- Return on investment: Refers is a new technology that would have the potential and opportunities for new revenue income. 
Table 2: A summary of the literature on external variables in the Building Information Modelling (BIM) TAM-T-O-E model.

\begin{tabular}{|c|c|c|c|c|c|c|c|c|c|c|c|c|c|c|c|c|c|c|c|c|c|c|c|c|c|c|}
\hline \multirow[b]{2}{*}{ Category } & \multirow[b]{2}{*}{ Code } & \multirow[b]{2}{*}{ External Variables } & \multicolumn{23}{|c|}{ References } & \multirow[t]{2}{*}{ sum } \\
\hline & & & $\mathrm{A}$ & B & $\begin{array}{ll} \\
\end{array}$ & $\bar{D}$ & E & $\mathrm{F}$ & $\bar{G}$ & $\mathrm{H}$ & & 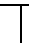 & $\mathrm{J}$ & $\mathrm{K}$ & \begin{tabular}{l|}
$\mathrm{L}$ \\
\end{tabular} & $\mathrm{M}$ & $\mathrm{N}$ & $\mathrm{O}$ & $\bar{P}$ & 10 & Q & \begin{tabular}{l|l}
$\mathrm{R}$ & \\
\end{tabular} & \begin{tabular}{l|l}
$S$ \\
\end{tabular} & $\bar{T}$ & $\mathrm{U}$ & \\
\hline \multirow{3}{*}{$\begin{array}{l}\text { Technological } \\
\text { Context }\end{array}$} & EV1 & Localization of BIM & & & & 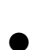 & & & & & & & & & & & $\bullet$ & $\bullet$ & 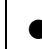 & 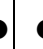 & 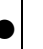 & - & & & 0 & 7 \\
\hline & EV2 & $\begin{array}{l}\text { Standardization } \\
\text { of BIM }\end{array}$ & - & $\bullet$ & 0 & & $\bullet$ & • & 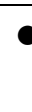 & 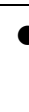 & & - & $\bullet$ & $\bullet$ & $\bullet$ & $\bullet$ & - & - & & 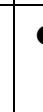 & $\boldsymbol{P}$ & $\bullet$ & - & $\bullet$ & $\bullet$ & 19 \\
\hline & EV3 & $\begin{array}{l}\text { Compatibility of } \\
\text { BIM }\end{array}$ & - & & - & 0 & • & & 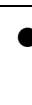 & 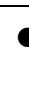 & & • & 0 & $\bullet$ & - & $\bullet$ & $\bullet$ & $\bullet$ & 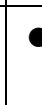 & 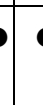 & $\boldsymbol{\bullet}$ & $\bullet$ & $\bullet$ & - & $\bullet$ & 19 \\
\hline \multirow{2}{*}{$\begin{array}{l}\text { Economic } \\
\text { Context }\end{array}$} & EV4 & Cost of using BIM & - & $\bullet$ & - & & $\bullet$ & $\bullet$ & 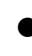 & & & $\bullet$ & $\bullet$ & - & & & $\bullet$ & $\bullet$ & & 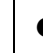 & • & $\bullet$ & $\bullet$ & $\bullet$ & & 15 \\
\hline & EV5 & $\begin{array}{l}\text { Return on } \\
\text { investment }\end{array}$ & & $\bullet$ & & & & - & e & 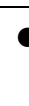 & & & - & & & & & & & & $\boldsymbol{\bullet}$ & & & & $\bullet$ & 7 \\
\hline \multirow{4}{*}{$\begin{array}{l}\text { Organisational } \\
\text { Context }\end{array}$} & EV6 & $\begin{array}{l}\text { Organisational } \\
\text { pattern and } \\
\text { workflow }\end{array}$ & - & - & - & & $\bullet$ & $\bullet$ & & s & & • & - & & - & $\bullet$ & $\bullet$ & $\bullet$ & & r & 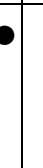 & - & & & $\bullet$ & 15 \\
\hline & EV7 & $\begin{array}{l}\text { Traditional } \\
\text { thinking mode }\end{array}$ & - & - & & & $\bullet$ & $\bullet$ & c & . & & • & - & & - & & - & & & . & 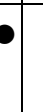 & - & & & - & 13 \\
\hline & EV8 & Executive support & $\bullet$ & & - & $\bullet$ & $\bullet$ & $\bullet$ & & & & & $\bullet$ & $\bullet$ & $\bullet$ & & & $\bullet$ & 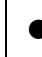 & P & $\bullet$ & $\bullet$ & & $\bullet$ & $\bullet$ & 15 \\
\hline & EV9 & $\begin{array}{l}\text { Number of BIM } \\
\text { experts and } \\
\text { technical staff }\end{array}$ & - & - & $\bullet$ & & $\bullet$ & & 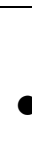 & & & & - & - & & & $\bullet$ & $\bullet$ & & . & • & $\bullet$ & - & & - & 13 \\
\hline \multirow{3}{*}{$\begin{array}{l}\text { Environmental } \\
\text { Context }\end{array}$} & EV10 & $\begin{array}{l}\text { Requirement from in the } \\
\text { industry }\end{array}$ & & - & - & & & $\bullet$ & e & & & & & & & $\bullet$ & & $\bullet$ & - & P & & & - & - & & 10 \\
\hline & EV11 & $\begin{array}{l}\text { Popularity of BIM } \\
\text { in the industry }\end{array}$ & & - & $\bullet$ & $\bullet$ & & & 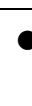 & 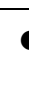 & & & - & & - & $\bullet$ & & & 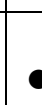 & & & & $\bullet$ & - & & 12 \\
\hline & EV12 & $\begin{array}{l}\text { Competitions } \\
\text { from other } \\
\text { companies }\end{array}$ & & & - & $\bullet$ & & & & & & & & & - & $\bullet$ & & $\bullet$ & 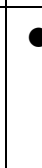 & & & & & & & 8 \\
\hline
\end{tabular}

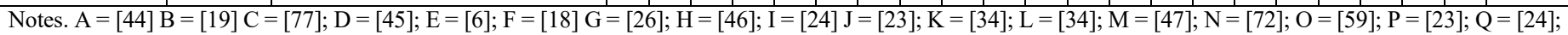
$\mathrm{R}=[48] ; \mathrm{S}=[8] ; \mathrm{T}=[26] ; \mathrm{U}=[22]$.

\subsection{Organisational factors}

As per [30], the four organisational factors can be listed as organisational mode and workflow, traditional thinking mode, support from senior management, and several experts and technicians.

- Organisational model and Workflow: It is normally fixed and is difficult to change the organisational model and workflow. Roles and responsibilities and work context frustrate application extension to a degree [30].

- Traditional Thinking mode: People are hesitant to change and handle issues in the same way [30], [24].
- Top Management Support: top management duty is one of the significant achievement factors for receiving BIM innovations [33].

- A number of BIM experts and technicians: The requirement of professionals with related technical experience and insights.

\subsection{Environmental factors.}

As per [30], environmental factors are shown at national, industrial, and enterprise levels for perceptions and attitudes in adoption and have been classified as national policy requirements, popularity in the BIM industry, and competition from other companies. 
- National policy requirements: As per [15], national policies is crucial to the development of information technology. For instance, the British government has assumed a significant part in advancing the application and the improvement of BIM [18].

- Popularity in the BIM industry: With greater acceptance, BIM adoption is becoming more popular.

- Competition from other companies: Completion can be clarified in two ways of competition namely, cost and differentiation.

The study merges TAM and TOE and proposes a Building Information Modelling (BIM) TAM-TOE model that consists of 12 external variables. An informative questionnaire was derived from the 12 external variables and 3 internal variables. A span number DEMATEL strategy was utilized to figure the impact degree, affected degree, centrality degree, and causal level of every factor. By ascertaining the centrality and reason for each factor, the key components influencing the selection of BIM are acquired, an 'impact and cause chart' was made dependent on the absolute relations between factors.

The study significant discoveries can be summed up as:

Firstly, the Requirement from public arrangements (EV10) is the most grounded driving variable, followed by Traditional thinking modes (EV7), Standardization of BIM (EV2), Compatibility of BIM (EV3), Competitions from other companies (EV12), Popularity of BIM in the industry (EV11), Localization of BIM and Return on investment (EV5).

Secondly, the re-enactments and emphases of the eight propulsive variables affirm that the objective variable Intention to use (IV3) fluctuated essentially and is responsive with changes of firstly, The Requirement from national policies (EV10), and then the Standardization of BIM (EV2).

\section{Conclusion}

TAM is a powerful adoption theory in the IT sector and has been used by numerous research studies. The model looks at an individual's goal when utilizing a system or application and recommend PU and PEOU as the central reason for IT adoption. Over the years TAM has shown great acceptance, utilization, and reproduction but the model failed to give essential data on the user's assumption to only PU and PEOU. Based on this limitation it was necessary for the model by expanding or integrating with other IT acceptance models [9]. The T-O-E framework proposed a generic set of factors of technology adoption. The T-O-E framework looks at three contexts namely Technology, Organisation, and Environmental. TAM and its all-encompassing forms have a high ability to clarify the innovation reception while the meaning of the T-O-E system is likewise perceived in clarifying technology adoption. The marriage of these two models brings a new and unique developed redesign that takes TAM and T-O-E models to a more extensive level to advance and encourage improved informative and prescient focal points of IT adoption.

The TAM and T-O-E framework can be used separately or as a hybrid depending on the situation at hand. In future it important to harmonize the so many factors of the models that have been suggested and used in literature.

This review paper doesn't overrule the acknowledgment of other reception models, yet it investigates the writing to create a selection model for study comparable data advances as referenced before.

\section{Acknowledgment}

This work is supported by the Vaal University of Technology under the supervision of Professor Tranos Zuva in Johannesburg (Vanderbijlpark), South Africa.

\section{References}

[1] C. Low, Y. Chen, M. Wu, "Understanding the determinants of cloud computing adoption," Industrial Management and Data Systems, 111(7), 1006-1023, 2011, doi:10.1108/02635571111161262.

[2] K. Zhu, K. Kraemer, S. Xu, "Electronic business adoption by European firms: A cross-country assessment of the facilitators and inhibitors," European Journal of Information Systems, 12(4), 251-268, 2003, doi:10.1057/palgrave.ejis.3000475.

[3] T.S.H. Teo, S. Lin, K. hung Lai, "Adopters and non-adopters of eprocurement in Singapore: An empirical study," Omega, 37(5), 972-987, 2009, doi:10.1016/j.omega.2008.11.001.

[4] M.I. Salwani, G. Marthandan, M.D. Norzaidi, S.C. Chong, "E-commerce usage and business performance in the Malaysian tourism sector: Empirical analysis," Information Management and Computer Security, 17(2), 66-185, 2009, doi:10.1108/09685220910964027.

[5] V. Venkatesh, F.D. Davis, M.G. Morris, "Dead or alive? The development, trajectory and future of technology adoption research," Journal of the Association for Information Systems, 8(4), 267-286, 2007, doi:10.17705/1jais.00120.

[6] S. Xu, K. Zhu, J. Gibbs, "Global Technology, Local Adoption: A CrossCountry Investigation of Internet Adoption by Companies in the United States and China," Electronic Markets, 14(1), 13-24, 2004, doi:10.1080/1019678042000175261.

[7] K. Zhu, K.L. Kraemer, V. Gurbaxani, S.X. Xu, Migration to open-standard interorganizational systems: Network effects, switching costs, and path dependency, MIS Quarterly: Management Information Systems, 2006, doi: $10.2307 / 25148771$.

[8] J. Xu, "Research on Application of BIM 5D Technology in Central Grand Project," in Procedia Engineering, 174 600-610, 2017, doi:10.1016/j.proeng.2017.01.194.

[9] H. Okorie Awa, O. Ukoha, B. Emecheta, "Integrating TAM and TOE Frameworks and Expanding their Characteristic Constructs for E-Commerce Adoption by SMEs," in Proceedings of the 2012 InSITE Conference, 571588, 2012, doi:10.28945/1676.

[10] C. Carnaghan, K. Klassen, "Exploring the determinants of web-based Ebusiness evolution in Canada," in Association for Information Systems 13th Americas Conference on Information Systems, AMCIS 2007: Reaching New Heights, 5 3532-3543, 2007.

[11] S. Alwahaishi, V. Snášel, "Modeling the Determinants Affecting Consumers' Acceptance and Use of Information and Communications Technology," International Journal of E-Adoption, 5(2), 25-39, 2013, doi:10.4018/jea.2013040103.

[12] Y.M. Wang, Y.S. Wang, Y.F. Yang, "Understanding the determinants of RFID adoption in the manufacturing industry," Technological Forecasting and Social Change, 77(5), 803-815, 2010, doi:10.1016/j.techfore.2010.03.006.

[13] Y.H. Li, "An empirical investigation on the determinants of E-procurement adoption in Chinese manufacturing enterprises," in 2008 International Conference on Management Science and Engineering 15th Annual Conference Proceedings, ICMSE, 32-37, 2008, doi:10.1109/ICMSE.2008.4668890.

[14] Y. a Au, H. Zafar, A Multi-Country Assessment of Mobile Payment Adoption, 2008, doi:10.1111/1467-8616.00112.

[15] N. Schillewaert, M.J. Ahearne, R.T. Frambach, R.K. Moenaert, "The adoption of information technology in the sales force," Industrial Marketing Management, 34(2), 323-336, 2005, doi:10.1016/j.indmarman.2004.09.013.

[16] M.J. Pan, W.Y. Jang, "Determinants of the adoption of enterprise resource planning within the technology-organization-environment framework: Taiwan's communications industry," Journal of Computer Information Systems, 48(3), 94-102, 2008, doi:10.1080/08874417.2008.11646025.

[17] K. Amoako-Gyampah, A.F. Salam, "An extension of the technology acceptance model in an ERP implementation environment," Information and Management, 41(6), 731-745, 2004, doi:10.1016/j.im.2003.08.010. 
[18] W.W. Wu, "Developing an explorative model for SaaS adoption," Expert Systems with Applications, 38(12), 15057-15064, 2011, doi:10.1016/j.eswa.2011.05.039.

[19] V. Venkatesh, M.G. Morris, G.B. Davis, F.D. Davis, "User acceptance of information technology: Toward a unified view," MIS Quarterly: Management Information Systems, 27(3), 425-478, 2003, doi: $10.2307 / 30036540$.

[20] O. Ukoha, H.O. Awa, C.A. Nwuche, I.F. Asiegbu, “Analysis of explanatory and predictive architectures and the relevance in explaining the adoption of IT in SMEs," Interdisciplinary Journal of Information, Knowledge, and Management, (6), 217-230, 2011, doi:10.28945/1431.

[21] I. Troshani, C. Jerram, H.S. Rao, "Industrial Management \&amp; Data Systems Exploring the public sector adoption of HRIS," Industrial Management \& Data Systems Personnel Review International Journal of Productivity and Performance Management Iss Kirstie S. Ball Personnel Review, 111(3), 470-488, 2011.

[22] S.Y. Yousafzai, G.R. Foxall, J.G. Pallister, Technology acceptance: a metaanalysis of the TAM: Part 1, Journal of Modelling in Management, 2007, doi:10.1108/17465660710834453.

[23] H.D. Yang, Y. Yoo, "It's all about attitude: Revisiting the technology acceptance model," Decision Support Systems, 38(1), 19-31, 2004, doi:10.1016/S0167-9236(03)00062-9.

[24] K. Zhu, K.L. Kraemer, S. Xu, "The Process of E-Business Assimilation in Organizations: A Technology Diffusion Perspective," Journal of the Institute for Operations Research and Management Sciences, 2005.

[25] L. Raymond, F. Bergeron, S. Blili, "The Assimilation of E-business in Manufacturing SMEs: Determinants and Effects on Growth and Internationalization," Electronic Markets, 2005, doi:10.1080/10196780500083761.

[26] M.D. Williams, Y.K. Dwivedi, B. Lal, A. Schwarz, "Contemporary trends and issues in IT adoption and diffusion research," Journal of Information Technology, 24(1), 1-10, 2009, doi:10.1057/jit.2008.30.

[27] I. Arpaci, O. Turetken, Y.C. Yardimci, S. Ozkan, "Organizational Adoption of Information Technologies: A Literature Review Telework View project Sentiment Analysis View project ORGANIZATIONAL ADOPTION OF INFORMATION TECHNOLOGIES: A LITERATURE REVIEW," INTERNATIONAL JOURNAL OF EBUSINESS AND EGOVERNMENT STUDIES, 4(2), 731-745, 2012.

[28] L. Silva, Post-positivist review of Technology Acceptance Model, Journal of the Association for Information Systems, 2007, doi:10.17705/1jais.00121.

[29] J.W. Moon, Y.G. Kim, "Extending the TAM for a World-Wide-Web context," Information and Management, 38(4), 217-230, 2001, doi:10.1016/S0378-7206(00)00061-6.

[30] X. Qin, Y. Shi, K. Lyu, Y. Mo, "USING A TAM-TOE MODEL TO EXPLORE FACTORS OF BUILDING INFORMATION MODELLING (BIM) ADOPTION IN THE CONSTRUCTION INDUSTRY," JOURNAL OF CIVIL ENGINEERING AND MANAGEMENT, 26(3), 463-468, 2020, doi:10.3846/jcem.2020.12176.

[31] P.A. Pavlou, "Consumer acceptance of electronic commerce: Integrating trust and risk with the technology acceptance model," International Journal of Electronic Commerce, 7(3), 101-134, 2003, doi:10.1080/10864415.2003.11044275.

[32] B. Ramdani, P. Kawalek, O. Lorenzo, "Predicting SMEs' adoption of enterprise systems," Journal of Enterprise Information Management, (22), 10-24, 2009, doi:10.1108/17410390910922796.

[33] M.S. Musawa, E. Wahab, "The adoption of electronic data interchange (EDI) technology by Nigerian SMEs: A conceptual framework," Journal of Business Management and Economics, 2012.

[34] H. Xu, J. Feng, S. Li, "Users-orientated evaluation of building information model in the Chinese construction industry," Automation in Construction, (39), 32-46, 2014, doi:10.1016/j.autcon.2013.12.004.

[35] K.W. Wen, Y. Chen, "E-business value creation in Small and Medium Enterprises: a US study using the TOE framework," International Journal of Electronic Business, 8(1), 80, 2010, doi:10.1504/ijeb.2010.030717.

[36] T. Oliveira, M.F. Martins, U.N. De Lisboa, "Literature Review of Information Technology Adoption Models at Firm Level," Review of Economics Studies, 2011.

[37] L. Da Chen, J. Tan, "Technology adaptation in E-commerce: Key determinants of virtual stores acceptance," European Management Journal, 22(1), 74-86, 2004, doi:10.1016/j.emj.2003.11.014.

[38] S. Priyanka, "Technology Acceptance Model: A Survey of Literature," International Journal of Business and Social Research (IJBSR), 2015.

[39] A.Y.L. Chong, B. Lin, K.B. Ooi, M. Raman, "Factors affecting the adoption level of c-commerce: An empirical study," Journal of Computer Information Systems, 50(2), 13-22, 2009, doi:10.1080/08874417.2009.11645380.

www.astesj.com
[40] W. Hong, K. Zhu, "Migrating to internet-based e-commerce: Factors affecting e-commerce adoption and migration at the firm level," Information and Management, 43(3), 204-221, 2006, doi:10.1016/j.im.2005.06.003.

[41] C. Zhang, L. Cui, L. Huang, C. Zhang, "Exploring the role of government in information technology diffusion: An empirical study of IT usage in Shanghai firms," in IFIP International Federation for Information Processing, 393-407, 2007, doi:10.1007/978-0-387-72804-9_26.

[42] A.N. Mishra, P. Konana, A. Barua, "Antecedents and consequences of Internet use in procurement: An empirical investigation of U.S. manufacturing firms," Information Systems Research, 18(1), 103-120, 2007, doi:10.1287/isre.1070.0115.

[43] N. Rao Kowtha, T. Whai Ip Choon, "Determinants of website development: A study of electronic commerce in Singapore," Information and Management, 39(3), 227-242, 2001, doi:10.1016/S0378-7206(01)00092-1.

[44] D. Mehran, "Exploring the Adoption of BIM in the UAE Construction Industry for AEC Firms," in Procedia Engineering, 2016, doi:10.1016/j.proeng.2016.04.144.

[45] L. Zhou, L. Dai, D. Zhang, "ONLINE SHOPPING ACCEPTANCE MODEL-A CRITICAL SURVEY OF CONSUMER FACTORS IN ONLINE SHOPPING (自己构造的模型, 列表写出了已存在的文献中 用于衡量 online shopping acceptance的factors, 分为两方面: online和 shopping ) , Journal of Electronic Commerce Research, 2007.

[46] Z. Zakaria, N. Mohamed Ali, A.T. Haron, A.M. Ponting, Z. Abd. Hamid, "Exploring the barriers and driving factors inimplementing Building Information Modeling (BIM) in the Malaysian Construction Industry: A Preliminary Study," The Journal of The Institution of Engineers, Malaysia, 58(12), 7250-7257, 2014.

[47] J. Won, G. Lee, C. Dossick, J. Messner, "Where to Focus for Successful Adoption of Building Information Modeling within Organization," Journal of Construction Engineering and Management, 139(11), 04013014, 2013, doi:10.1061/(asce)co.1943-7862.0000731.

[48] R. Bose, X. Luo, "Integrative framework for assessing firms' potential to undertake Green IT initiatives via virtualization - A theoretical perspective," Journal of Strategic Information Systems, 110(2), 269-283, 2011, doi:10.1016/j.jsis.2011.01.003. 